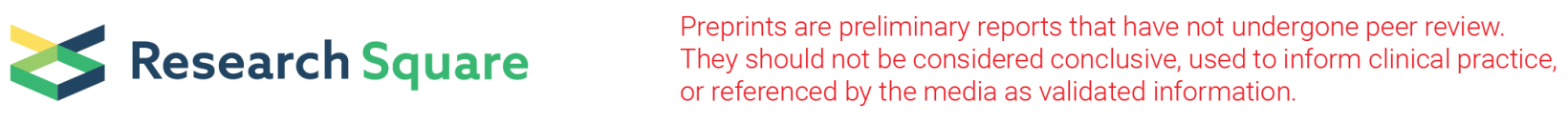

\title{
Detection of Multidrug-resistant Extended-spectrum Beta-lactamase- producing Enterobacteria from Community Infections in the city of Reynosa, Tamaulipas Mexico
}

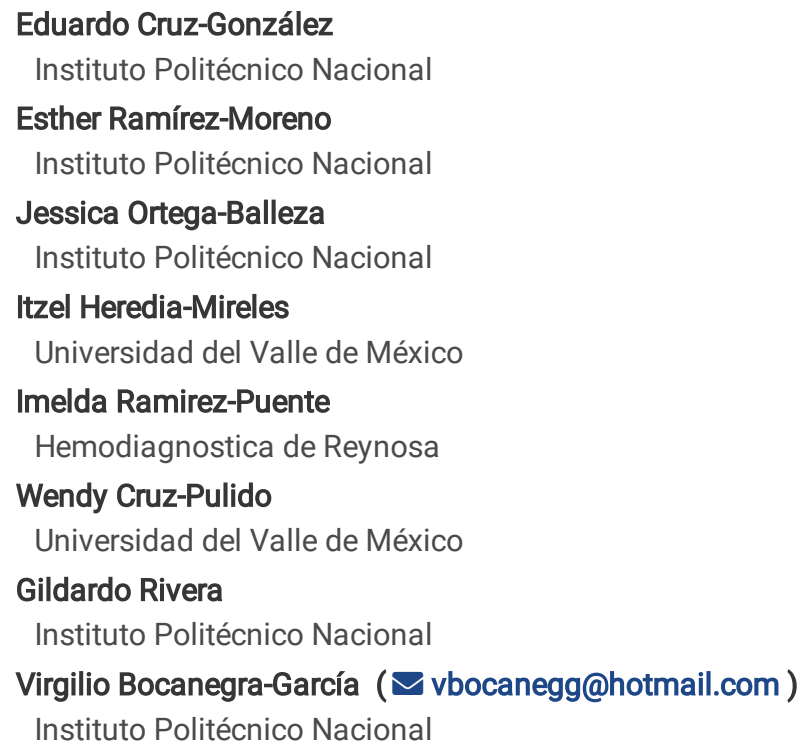




\section{Abstract}

Production of extended spectrum beta-lactamases (ESBL) is one of the main problems related to antimicrobial resistance worldwide, with the CTX-M, TEM and SHV types standing out as the most prevalent. These enzymes are usually related to plasmids which facilitates their horizontal genetic transmission. In the northeast region of Tamaulipas their clinical prevalence is unknown. Therefore, the aim of this work was to define the molecular epidemiology of ESBL-producing Enterobacteriaceae in clinical strains collected in Reynosa Tamaulipas, Mexico. A selection of 123 Enterobacteriaceae strains from different clinical patients were collected from August 2018 to December 2019. These strains were phenotypically identified by double disk synergy tests (DDST) and subsequently subjected to polymerase chain reaction for the detection and amplification of the $b / a_{\mathrm{TEM}}, b / a_{\mathrm{SHV}}, b / a_{\mathrm{CTX}-\mathrm{M}-1}, b / a_{\mathrm{CTX}-\mathrm{M}-2}, b / a_{\mathrm{CTX}-\mathrm{M}-9}$ and $b / a_{\mathrm{CTX}-\mathrm{M}-8 / 25}$ genes. Lastly, antimicrobial resistance profiles were determined by plate diffusion method and their capacity to transfer this sort of resistance by conjugation was assessed. Our results showed a prevalence of $48.78 \%(60 / 123)$ of ESBL-producing enterobacteria, with the bla $a_{\text {TEM }}$ and bla $a_{\text {CTX-M-1 }}$ genes most commonly detected in $76.67 \%$ (46/60) and 58.33\% (35/60), respectively. Additionally, a 68.33\% (41/60) of these ESBL-producing Enterobacteriaceae were multidrugresistant, while $51.67 \%$ (31/60) were able to transfer some genes related to ESBL production, being bla $a_{\mathrm{CTX}-\mathrm{M}-1}$ the most common. This is the first study in the region that evaluates ESBL production in clinical Enterobacteriaceae strains, as well as the content of genes related to this phenotype and the ability to transfer this type of antimicrobial resistance.

\section{Introduction}

Antimicrobial resistance is currently a great challenge in the clinical environment, since it complicates the treatment, control, and prevention of a growing number of infections [1, 2, 3]. Infections related to multidrug-resistant bacteria (MDR) have led to the use of broad-spectrum antibiotics such as third and fourth generation cephalosporins and carbapenems, causing an increase on selective pressure that has favored the proliferation and dissemination of resistant strains [4, 5]. Extended-spectrum beta-lactamases (ESBL) producing Enterobacteriaceae are considered by the World Health Organization (WHO) as priority microorganisms for the development of new antibiotics, as well as for microbial resistance monitoring [6]. ESBL production confers resistance to most penicillins, to first, second, and third generation cephalosporins and to monobactams $[7,8,9]$. ESBLs belong to classes A and D of Ambler's beta-lactamases classification and are characterized by containing a serine residue in its active site, in addition to being strongly inhibited by classical inhibitors such as clavulanic acid [10]. ESBLs groups includes nine structural families: TEM, SHV, CTX-M, PER, VEB, GES, TLA, BES and OXA [11]. The TEM, SHV and CTX-M families are the most prevalent worldwide reported in hospital and community infections $[6,12,13]$. ESBLs contained in conjugative plasmids facilitate their mobility through horizontal gene transfer $[11,14,15]$ and in turn, these plasmids may contain resistance related genes to other antibiotics, such as quinolones, aminoglycosides, tetracyclines and even colistin, which increases the chances of failure in treatment schemes [16, 17, 18].

ESBL-producing Enterobacteriaceae were originally associated with infections related to the hospital environment, however, cases of community-associated infections have increased [5], and ESBL-producing Enterobacteriaceae have been reported in sources, such as water, soil, livestock, pets and in healthy human carriers $[15,19]$. In the northeast region of Tamaulipas, the presence of ESBL-producing Enterobacteriaceae has been reported in animal origin food and superficial waters [20]. However, there is little information regarding the prevalence of such microorganisms of clinical origin. The aim of the present work was to define the molecular epidemiology of ESBLproducing Enterobacteriaceae in clinical strains isolated in the city of Reynosa, Tamaulipas in the northeast region of Mexico, in addition to identify the genotype related to ESBL production, determine their microbial resistance profile and lastly, to evaluate their capacity to transfer this resistance.

\section{Results}

\section{ESBL-producing Enterobacteriaceae Distribution.}

A total of 123 Enterobacteriaceae strains were analyzed, of which 61.79\% (76/123) presented resistance to CTX, and 48.78\% (60/123) were identified as ESBL producers. ESBL-producing strains were mostly found in isolates from diabetic foot wounds (16 strains), urinary tract infections (15 strains), bronchial secretions (8 strains), wounds (7 strains), stool (3 strains), urethral secretions (2 strains), vaginal exudates (2 strains), expectorations (2), bronchial aspiration (2 strains), ulcers (2 strains) and lithotomy (1 strain). Of the identified ESBL producers, Escherichia coli $(26 / 60)$ strains stood out, followed by Klebsiella pneumoniae $(11 / 60)$ among other species as shown in Table 1. 
Table 1

Distribution of ESBL-related genes.

\begin{tabular}{|c|c|c|c|c|c|c|c|c|}
\hline \multirow[t]{2}{*}{ Species } & \multirow{2}{*}{$\begin{array}{l}\text { Number of } \\
\text { strains }\end{array}$} & \multirow{2}{*}{$\begin{array}{l}\text { Positive strains for } \\
\text { some ESBL gene }\end{array}$} & \multicolumn{6}{|c|}{ ESBL Genes } \\
\hline & & & $b / a_{\mathrm{TEM}}$ & $b a_{\text {SHV }}$ & bla $_{\text {CTX-M-1 }}$ & $b / a_{\mathrm{CTX}-\mathrm{M}-2}$ & $b^{b} a_{\mathrm{CTX}-\mathrm{M}-9}$ & bla $_{\text {CTX-M-8/25 }}$ \\
\hline $\begin{array}{l}\text { Citrobacter } \\
\text { koseri }\end{array}$ & 2 & 2 & 2 & 1 & 2 & 0 & 0 & 1 \\
\hline $\begin{array}{l}\text { Edwardsiella } \\
\text { tarda }\end{array}$ & 1 & 1 & 1 & 0 & 0 & 0 & 0 & 0 \\
\hline $\begin{array}{l}\text { Enterobacter } \\
\text { cloacae }\end{array}$ & 1 & 1 & 1 & 0 & 1 & 0 & 0 & 0 \\
\hline $\begin{array}{l}\text { Erwinia } \\
\text { chrysanthemi }\end{array}$ & 2 & 2 & 2 & 0 & 0 & 0 & 0 & 0 \\
\hline Escherichia coli & 26 & 24 & 19 & 0 & 15 & 1 & 2 & 2 \\
\hline $\begin{array}{l}\text { Klebsiella } \\
\text { aerogenes }\end{array}$ & 4 & 4 & 4 & 0 & 3 & 1 & 1 & 3 \\
\hline $\begin{array}{l}\text { Klebsiella } \\
\text { oxytoca }\end{array}$ & 1 & 0 & 0 & 0 & 0 & 0 & 0 & 0 \\
\hline $\begin{array}{l}\text { Klebsiella } \\
\text { pneumoniae }\end{array}$ & 11 & 10 & 9 & 4 & 6 & 1 & 2 & 3 \\
\hline $\begin{array}{l}\text { Providencia } \\
\text { stuartii }\end{array}$ & 1 & 1 & 1 & 0 & 1 & 0 & 0 & 1 \\
\hline $\begin{array}{l}\text { Serratia } \\
\text { liquefaciens }\end{array}$ & 4 & 3 & 2 & 1 & 3 & 0 & 0 & 2 \\
\hline $\begin{array}{l}\text { Serratia } \\
\text { marcescens }\end{array}$ & 2 & 2 & 1 & 0 & 1 & 1 & 1 & 0 \\
\hline Shigella sonnei & 5 & 5 & 4 & 0 & 3 & 0 & 1 & 3 \\
\hline Total & 60 & 55 & 46 & 6 & 35 & 4 & 7 & 15 \\
\hline
\end{tabular}

\section{ESBL-producing Enterobacteriaceae Genomic Characterization.}

Of the 60 phenotypically positive strains, it was possible to identify the presence of genes related to the production of ESBL in $91.67 \%$ of the analyzed strains (55/60). The bla $a_{\mathrm{TEM}}$ gene was the most commonly found, in $76.67 \%(46 / 60)$ of the strains, followed by the bla $\mathrm{CTX}-\mathrm{M}-1$ group with $58.33 \%$ (35/60) and the bla $a_{\mathrm{CTX}-\mathrm{M}-8 / 25}$ group with $25 \%$ (15/60). Additionally, the bla $a_{\mathrm{CTX}-\mathrm{M}-9}, b_{\mathrm{SHV}}$ and bla $a_{\mathrm{CTX}-\mathrm{M}-2}$ genes were found in $11.67 \%(77 / 60), 10 \%(6 / 60)$ and $6.67 \%(4 / 60)$ of the strains, respectively. Considering the number of genes per strain, a $40 \%$ of the strains $(24 / 60)$ only presented the presence of one gene, while in $23.33 \%(14 / 60)$ two genes were detected; subsequently, in $15 \%$ of the strains ( $9 / 60)$ three genes were identified, in $11.67 \%$ (7/60) four genes were detected, while in one strain, five genes related to ESBL production were detected. On the other hand, $3.33 \%(5 / 60)$ of the strains were negative for the surveyed genes. 
Table 2

ESBL-producing Enterobacteriaceae Resistance Profiles

\begin{tabular}{|c|c|c|c|c|c|c|c|c|c|c|c|c|c|c|c|c|c|}
\hline \multirow[t]{2}{*}{ Species } & \multirow{2}{*}{$\begin{array}{l}\text { Number } \\
\text { of } \\
\text { strains }\end{array}$} & \multicolumn{16}{|c|}{ Resistance Incidence } \\
\hline & & AM & AMC & ATM & CTX & CAZ & CRO & FEP & GM & AN & CIP & NA & LEV & STX & $C$ & FM & TE \\
\hline $\begin{array}{l}\text { Citrobacter } \\
\text { koseri }\end{array}$ & 2 & 2 & 1 & 2 & 2 & 1 & 2 & 2 & 1 & 0 & 1 & 1 & 1 & 2 & 2 & 1 & 1 \\
\hline $\begin{array}{l}\text { Edwardsiella } \\
\text { tarda }\end{array}$ & 1 & 1 & 0 & 0 & 1 & 0 & 1 & 1 & 1 & 0 & 1 & 0 & 1 & 1 & 0 & 0 & 1 \\
\hline $\begin{array}{l}\text { Enterobacter } \\
\text { cloacae }\end{array}$ & 1 & 0 & 1 & 1 & 1 & 1 & 0 & 0 & 0 & 0 & 0 & 0 & 0 & 0 & 0 & 0 & 1 \\
\hline $\begin{array}{l}\text { Erwinia } \\
\text { chrysanthemi }\end{array}$ & 2 & 2 & 2 & 1 & 2 & 0 & 2 & 2 & 1 & 0 & 1 & 2 & 1 & 2 & 1 & 2 & 2 \\
\hline $\begin{array}{l}\text { Escherichia } \\
\text { coli }\end{array}$ & 26 & 22 & 15 & 20 & 25 & 21 & 25 & 13 & 10 & 5 & 15 & 13 & 13 & 17 & 10 & 11 & 11 \\
\hline $\begin{array}{l}\text { Klebsiella } \\
\text { aerogenes }\end{array}$ & 4 & 3 & 3 & 4 & 4 & 4 & 2 & 1 & 1 & 0 & 1 & 1 & 1 & 2 & 1 & 1 & 1 \\
\hline $\begin{array}{l}\text { Klebsiella } \\
\text { oxytoca }\end{array}$ & 1 & 1 & 1 & 1 & 1 & 1 & 1 & 1 & 0 & 0 & 1 & 0 & 1 & 0 & 1 & 0 & 0 \\
\hline $\begin{array}{l}\text { Klebsiella } \\
\text { pneumoniae }\end{array}$ & 11 & 8 & 6 & 11 & 10 & 9 & 8 & 6 & 3 & 1 & 3 & 3 & 3 & 7 & 1 & 6 & 5 \\
\hline $\begin{array}{l}\text { Providencia } \\
\text { stuartii }\end{array}$ & 1 & 1 & 1 & 1 & 1 & 1 & 1 & 1 & 1 & 1 & 1 & 1 & 1 & 1 & 1 & 1 & 1 \\
\hline $\begin{array}{l}\text { Serratia } \\
\text { liquefaciens }\end{array}$ & 4 & 4 & 4 & 3 & 4 & 2 & 3 & 1 & 1 & 0 & 2 & 3 & 2 & 3 & 3 & 3 & 1 \\
\hline $\begin{array}{l}\text { Serratia } \\
\text { marcescens }\end{array}$ & 2 & 2 & 2 & 1 & 2 & 2 & 2 & 0 & 0 & 0 & 1 & 2 & 1 & 2 & 2 & 2 & 0 \\
\hline $\begin{array}{l}\text { Shigella } \\
\text { sonnei }\end{array}$ & 5 & 5 & 4 & 5 & 5 & 5 & 4 & 3 & 2 & 1 & 3 & 4 & 3 & 4 & 4 & 5 & 4 \\
\hline Total & 60 & 51 & 40 & 50 & 58 & 47 & 51 & 31 & 21 & 8 & 30 & 30 & 28 & 41 & 26 & 32 & 28 \\
\hline
\end{tabular}

\section{Antimicrobial Resistance Profiles.}

Antimicrobial resistance profiles of the ESBL-producing strains are shown in Table 2. We observed a high resistance to the beta-lactams included in this study, with resistance to CTX being the most common found in $96.67 \%(58 / 60)$ of ESBL-producing Enterobacteriaceae. We can highlight high ranges of resistance to STX, quinolones and TE; while AN turned out to be the most effective antibiotic against the ESBLproducing strains studied in this work. On the other hand, it should be noted that $66.67 \%(40 / 60)$ of the ESBL-producing strains presented the MDR phenotype since it showed resistance to 3 or more classes of antibiotics used in this work.

\section{ESBL Horizontal Gene Transfer.}

The conjugation assay was successful (Table 3 ) in 51.67\% (31/60) of the experiments. With CTX-M as the main beta-lactamases type transferred, followed by TEM, while SHV did not succeed in being transferred. It is worth mentioning that 15 strains transferred more than one gene, with 10 (32.26\%) and 5 (16.13\%) being able to transfer two and three genes, respectively. 
Table 3

Distribution and Frequency of ESBL Genes Successfully Transferred by Conjugation

\begin{tabular}{|c|c|c|c|c|c|c|c|c|}
\hline \multirow[t]{2}{*}{ Donor strains } & \multirow{2}{*}{$\begin{array}{l}\text { Conjugation } \\
\text { successful }\end{array}$} & \multirow{2}{*}{$\begin{array}{l}\text { Multiple ESBLs } \\
\text { transferred }\end{array}$} & \multicolumn{6}{|c|}{ Main ESBL genes transferred } \\
\hline & & & bla TEM & bla $_{\text {SHV }}$ & $b / a_{\mathrm{CTX}-\mathrm{M}-1}$ & $b^{b} a_{\mathrm{CTX}-\mathrm{M}-2}$ & bla $\mathrm{CTX}-\mathrm{M}-9$ & $b / a_{\mathrm{cTX}-\mathrm{M}-8 / 25}$ \\
\hline $\begin{array}{l}\text { Citrobacter } \\
\text { koseri }\end{array}$ & 2 & 1 & 1 & 0 & 1 & 0 & 0 & 1 \\
\hline Escherichia coli & 15 & 2 & 6 & 0 & 9 & 0 & 0 & 2 \\
\hline $\begin{array}{l}\text { Klebsiella } \\
\text { aerogenes }\end{array}$ & 3 & 3 & 1 & 0 & 3 & 0 & 0 & 3 \\
\hline $\begin{array}{l}\text { Klebsiella } \\
\text { pneumoniae }\end{array}$ & 5 & 3 & 2 & 0 & 3 & 0 & 1 & 3 \\
\hline $\begin{array}{l}\text { Providencia } \\
\text { stuartii }\end{array}$ & 1 & 1 & 1 & 0 & 1 & 0 & 0 & 1 \\
\hline $\begin{array}{l}\text { Serratia } \\
\text { liquefaciens }\end{array}$ & 2 & 2 & 1 & 0 & 2 & 0 & 0 & 2 \\
\hline Shigella sonnei & 3 & 3 & 1 & 0 & 3 & 0 & 0 & 3 \\
\hline Total & 31 & 15 & 13 & 0 & 22 & 0 & 1 & 15 \\
\hline
\end{tabular}

\section{Discussion}

ESBL-mediated resistance in Enterobacteriaceae is one of the greatest threats to public health at present, increasing morbidity and mortality of many infectious diseases, in addition to increasing health costs. There are different reports in Mexico regarding the presence and mobility of ESBL-producing strains and the genes associated with their production [12, 19, 21, 22, 2, 25]. However, in the northeast region of Mexico only the environmental distribution of these organisms has been elucidated [20].

Our results showed that $48.78 \%$ of analyzed Enterobacteriaceae presented the characteristic ESBL-production phenotype, being $E$. coli and $K$. pneumoniae the most common species which presented this phenotype; similar results have been reported in different countries [26, 27]. Although K. pneumoniae has stood out as one of the most common producers of ESBLs, it should be noted that in recent years, ESBLproducing E. coli has gained importance worldwide [28, 29]. Most of the ESBL-producing isolates were isolated from diabetic foot wounds and urinary tract infections (UTIs). As for UTIs, Enterobacteriaceae, specifically E. coli stands out as one of the main etiological agents of these sort of infections [30], while in diabetic foot infections E. coli and K. pneumoniae stands out together with Pseudomonas aeruginosa, Enterococcus spp. Staphylococcus aureus as common infectious agents related to these wounds. In addition to this, cephalosporins are part of the empirical antimicrobial treatment which could compromise said therapy by prolonging the morbidity of these conditions [30, 31].

Regarding ESBL-related genes, most of the analyzed strains in the present work were found to be related to the TEM type and group 1 of the CTX-M type, while those of the SHV type were found to be less prevalent; although it should be mentioned that the prevalence of ESBL genes varies greatly depending on the geographical region [32]. An interesting fact is that ESBLs of TEM and SHV types had been the main described genetic antimicrobial resistance determinants during much of the 2000s, however, we reported a very low prevalence of the SHV type and an increase in the CTX-M type, which is considered an emerging beta-lactamase. This may be due to the fact that CTX-M type ESBLs come from an environmental Enterobacteriaceae, which increases the possibilities of acquiring a CTX-M-producing Enterobacteriaceae in the community [28]. An 8.33\% (5/60) of analyzed strains presented the ESBL-related phenotype but lacked the searched ESBLs in this work, however, the presence of some different ESBL that was not included in the present work is not discarded.

Lastly, 51.67\% (31/60) of analyzed Enterobacteriaceae in this work had the ability to transfer resistance to 3rd. generation cephalosporins, being the CTX-M-1 type beta-lactamase the predominant transferred type in 23/31 trans-conjugating strains, in comparison with the TEM type (13/31). This is relevant due to the CTX-M type beta-lactamase can be mobilized by environmental Enterobacteriaceae, and it has been reported that sub-therapeutic concentrations of cephalosporins can increase their ability to transfer genes related to CTX-M beta-lactamases $[33,34]$. In addition, $66.67 \%(40 / 60)$ of the ESBL-producing strains showed resistance to more than 3 antibiotic families, which indicates the spread of MDR phenotype in ESBL-producing Enterobacteriaceae which could drastically reduce treatment options [4]. Amikacin stood out as the most effective antibiotic, which has already been reported in previous works and this can constitute a treatment option of infections caused by these antimicrobial-resistant microorganisms [35, 36]. 
To our knowledge, this is the first work that focuses on studying production of ESBLs, genomic type and evaluation of horizontal gene transfer potential of ESBL genes in clinical Enterobacteriaceae strains in the northeast region of Tamaulipas. Described findings can give us an insight of the current outlook regarding the state of resistance to 3rd generation cephalosporins and other families of antibiotics in the region.

Collected data will allow us to develop possible treatment schemes and to evaluate key points related to the current antimicrobial resistance in the region.

\section{Methods}

\section{Strain Selection.}

Strains were obtained from the Environment-Microorganism Interaction Laboratory's biobank of the Centro de Biotecnología Genómica of the Instituto Politécnico Nacional and private laboratories of the city of Reynosa, Tamaulipas. A total of 123 Enterobacteriaceae strains were selected from bronchial aspiration samples (6), vaginal exudates (5), expectoration samples (5), stool samples (14), wounds (6), lithotomy (1), urine samples (37), diabetic foot wounds (42), bronchial secretions (3), ulcers (3), and urethral secretions (1). Strains were isolated and identified during the period from August 2018 to December 2019.

\section{ESBL Phenotypic Detection Assays.}

Strains were subcultured in tryptic soy agar medium (BD Becton Dickinson \& Co) supplemented with $2 \mu \mathrm{g} . / \mathrm{mL}$. of cefotaxime (CTX). Those presenting resistance to cefotaxime (CTX) were tested to detect phenotypic ESBL production by double-disk synergy test (DDST) using cefotaxime (CTX $30 \mu \mathrm{g}$.), ceftazidime (CAZ $30 \mu \mathrm{g}$.), aztreonam (ATM $30 \mu \mathrm{g}$.) and cefepime (FEP $30 \mu \mathrm{g}$.) (BBL ${ }^{\mathrm{TM}}$ Sensi-Disc $^{\mathrm{T}}$ ). This test was performed by placing a disc containing amoxicillin with clavulanic acid (AMC $30 \mu \mathrm{g}$.) in the center of the plate to observe the synergy phenomenon when the inhibition halo increased towards the AMC disc, to consider the strain as positive phenotypic [37].

\section{Generation of Antimicrobial Resistance Genetic Profiles.}

Antimicrobial resistance profiles were determined by plate diffusion method for ampicillin (AM $30 \mu \mathrm{g}$.), AMC, ceftriaxone (CRO $30 \mu \mathrm{g}$.), CTX, CAZ, ATM, FEP, amikacin (AK $30 \mu \mathrm{g}$.), gentamicin (GM $10 \mu \mathrm{g}$.), ciprofloxacin (CIP $5 \mu \mathrm{g}$. ), levofloxacin (LXV $5 \mu \mathrm{g}$.$) , nalidixic acid (NA 30 \mu \mathrm{g}$.), trimethoprim/sulfamethoxazole (SXM 1. 25/23. $75 \mu \mathrm{g}$.), chloramphenicol (C $30 \mu \mathrm{g}$.) (BBL ${ }^{\mathrm{TM}}$ Sensi-Disc ${ }^{\mathrm{TM}}$ ), nitrofurantoin (FM $300 \mu \mathrm{g}$.) and tetracycline (TE $30 \mu \mathrm{g}$.); tests were performed according to the Clinical and Laboratory Standards Institute (CLSI, 2020) criteria, using Escherichia coli ATCC $\circledast 25922^{\text {TM }}$ as negative control.

\section{ESBL-related Genes Characterization.}

The presence of the bla $a_{\text {TEM }}, b / a_{\text {SHV }}$ and bla $a_{C T X-M}$ was detected by multiplex PCR [38], the primers used are shown in the Table 4. PCR was performed with a final volume of $15 \mu \mathrm{L}$., comprising $1 x$ buffer, $25 \mathrm{mM} \mathrm{MgCl} 2,10 \mathrm{mM}$ dNTPs, $10 \mathrm{mM}$ of each primer and $5 \mathrm{U}$ of GoTaq ${ }^{\circledR}$ Flexi DNA Polymerase (Promega, USA). The used amplification program consists of a first step of $94^{\circ} \mathrm{C}$ for $1 \mathrm{~min}, 30 \mathrm{cycles}$ of $94^{\circ} \mathrm{C}$ for $40 \mathrm{~s}, 60^{\circ} \mathrm{C}$ for $40 \mathrm{~s}$ and $72{ }^{\circ} \mathrm{C}$ for $1 \mathrm{~min}$, with one last step of $72{ }^{\circ} \mathrm{C}$ for $7 \mathrm{~min}$. PCR amplicons were visualized on a $2 \%$ agarose gel electrophoresis performed at $100 \mathrm{~V}$ for 1 hour and stained with SYBR Gold ${ }^{\mathrm{TM}}$ (Thermo Fisher Scientifc, USA) to be observed on a UV KODAK Gel Logic 100 transilluminator. 
Table 4

Specific Primers Used for The Detection of ESBL Groups

\begin{tabular}{|c|c|c|}
\hline Target & Sequence $\left(5^{\prime}-3^{\prime}\right)$ & Amplicon size (bp) \\
\hline \multirow[t]{2}{*}{ TEM } & CATTTCCGTGTCGCCCTTATTC & 800 \\
\hline & CGTTCATCCATAGTTGCCTGAC & \\
\hline \multirow[t]{2}{*}{ SHV } & AGCCGCTTGAGCAAATTAAAC & 713 \\
\hline & ATCCCGCAGATAAATCACCAC & \\
\hline \multirow[t]{2}{*}{ CTX group 1} & TTAGGAARTGTGCCGCTGYA & 688 \\
\hline & CGATATCGTTGGTGGTRCCAT & \\
\hline \multirow[t]{2}{*}{ CTX group 2} & CGTTAACGGCACGATGAC & 404 \\
\hline & CGATATCGTTGGTGGTRCCAT & \\
\hline \multirow[t]{2}{*}{ CTX group 9} & TCAAGCCTGCCGATCTGGT & 561 \\
\hline & TGATTCTCGCCGCTGAAG & \\
\hline \multirow[t]{2}{*}{ CTX group $8 / 25$} & AACRCRCAGACGCTCTAC & 326 \\
\hline & TCGAGCCGGAASGTGTYAT & \\
\hline
\end{tabular}

\section{Conjugation Potential Tests.}

Conjugation tests were performed using the sodium azide-resistant $E$. coli strain $\mathrm{J} 53$ as a recipient. Both, the donor strain and the recipient strain were grown separately at $37^{\circ} \mathrm{C}$ overnight in Luria Bertani broth (BD Becton Dickinson \& Co.). Conjugation tests were carried out mixing equal volumes in a 1:1 ratio of the donor and the recipient strains for their subsequent incubation at $37^{\circ} \mathrm{C}$ for 4 hours. After incubation, they were cultured on tryptic soy agar medium plates supplemented with $2 \mu \mathrm{g} . / \mathrm{mL}$. of CTX and $100 \mu \mathrm{g}$./mL. of sodium azide to eliminate donor strains. Positive strains were assayed for the detection of ESBL production-related genes.

\section{Declarations}

\section{Author contributions}

V.B.G. and E.R.M. contributed to the conception and design of this study; J.O.B., I.H.M., I. R. P., W. C. P. and, E.C.G. collected the samples and performed the experiments, E.C.G. wrote the manuscript. V.B.G., G. R., and E.R.M., reviewed the manuscript.

\section{Competing interests}

The authors declare no competing interests.

\section{References}

1. Robinson, T. P. et al. Antibiotic resistance is the quintessential One Health issue. Transactions of the Royal Society of Tropical Medicine and Hygiene, 110(7), 377-380. (2016).

2. Tacconelli, E. et al. Surveillance for control of antimicrobial resistance. The Lancet. Infectious diseases, 18(3), e99-e106. https://doi.org/10.1016/S1473-3099(17)30485-1 (2018).

3. Bubpamala, J. et al. Phenotypic and genotypic characterizations of extended-spectrum beta-lactamase-producing Escherichia coli in Thailand. Infection and drug resistance, 11, 2151-2157. (2018).

4. Park, S. Y. et al. Risk factors and molecular epidemiology of community-onset, multidrug resistance extended-spectrum $\beta$-lactamaseproducing Escherichia coli The Korean journal of internal medicine, 32(1), 146-157. (2017).

5. Tanner, W. D. et al. Multi-state study of Enterobacteriaceae harboring extended-spectrum beta-lactamase and carbapenemase genes in U.S. drinking water. Scientific reports, 9(1), 3938. https://doi.org/10.1038/s41598-019-40420-0 (2019).

6. Zhou, K. et al. Dissemination of a 'rare'extended-spectrum $\beta$-lactamase gene blaSFO-1 mediated by epidemic clones of carbapenemaseproducing Enterobacter hormaechei in China. International Journal of Antimicrobial Agents, 56(3), 106079. 
https://doi.org/10.1016/j.ijantimicag.2020.106079 (2020).

7. El-Jade, M. R. et al. ESBL Detection: Comparison of a Commercially Available Chromogenic Test for Third Generation Cephalosporine Resistance and Automated Susceptibility Testing in Enterobactericeae. PloS one, 11(8), e0160203. https://doi.org/10.1371/journal.pone.0160203 (2016).

8. Ye, Q. et al. Antibiotic-Resistant Extended Spectrum ß-Lactamase- and Plasmid-Mediated AmpC-Producing Enterobacteriaceae Isolated from Retail Food Products and the Pearl River in Guangzhou, China. Frontiers in microbiology, 8, 96. https://doi.org/10.3389/fmicb.2017.00096 (2017).

9. Clasen, J., Birkegård, A. C., Græsbøll, K., \& Folkesson, A. Evolution of TEM-type extended-spectrum $\beta$-lactamases in Escherichia coli by cephalosporins. Journal of global antimicrobial resistance, 19, 32-39. (2019).

10. Bush, K., \& Jacoby, G. A. Updated functional classification of beta-lactamases. Antimicrobial agents and chemotherapy, 54(3), 969-976. (2010).

11. Li, J. et al. Detection of the SHV genotype polymorphism of the extended-spectrum $\beta$-lactamase-producing Gram-negative bacterium. Biomedical reports, 3(2), 261-265. (2015).

12. Miranda-Romero, A. L. et al., Molecular characterization of ESBL-producing Escherichia coli isolates from hospital- and communityacquired infections in NW Mexico. Diagnostic microbiology and infectious disease, 87(1), 49-52. (2017).

13. Jin, W. et al. Structural Insights into the TLA-3 Extended-Spectrum $\beta$-Lactamase and Its Inhibition by Avibactam and OP0595. Antimicrobial agents and chemotherapy, 61(10), e00501-17. https://doi.org/10.1128/AAC.00501-17 (2017).

14. Alcántar-Curiel, M. D. et al. Association of Antibiotic Resistance, Cell Adherence, and Biofilm Production with the Endemicity of Nosocomial Klebsiella pneumoniae. BioMed research international, 2018, https://doi.org/10.1155/2018/7012958 (2018).

15. von Tippelskirch, P. et al. Prevalence and quantitative analysis of ESBL and AmpC beta-lactamase producing Enterobacteriaceae in broiler chicken during slaughter in Germany. International journal of food microbiology, 281, 82-89. (2018).

16. Zhao, J. Y. et al. Coexistence of SFO-1 and NDM-1 $\beta$-lactamase genes and fosfomycin resistance gene fosA3 in an Escherichia coli clinical isolate. FEMS microbiology letters, 362(1), 1-7. (2015).

17. Wu, C. et al. Rapid rise of the ESBL and mcr-1 genes in Escherichia coli of chicken origin in China, 2008-2014. Emerging microbes \& infections, $7(1)$, https://doi.org/10.1038/s41426-018-0033-1 (2018).

18. Wangkheimayum, J. et al. Expansion of acquired 16S rRNA methytransferases along with CTX-M-15, NDM and OXA-48 within three sequence types of Escherichia coli from northeast India. BMC infectious diseases, 20(1), https://doi.org/10.1186/s12879-020-05264-4 (2020).

19. Cortés-Cortés, G. et al. Extended-spectrum $\beta$-lactamase-producing Escherichia coli isolated from healthy humans in Mexico, including subclone ST131-B2-O25:H4-H30-Rx. Journal of global antimicrobial resistance, 9, 130-134. https://doi.org/10.1016/j.jgar.2017.02.014 (2017).

20. Martínez-Vázquez, A. V., Rivera-Sánchez, G., Lira-Méndez, K., Reyes-López, M. Á., \& Bocanegra-García, V. Prevalence, antimicrobial resistance and virulence genes of Escherichia coli isolated from retail meat in Tamaulipas, Mexico. Journal of global antimicrobial resistance, 14, 266-272. https://doi.org/10.1016/j.jgar.2018.02.016 (2018).

21. Cornejo-Juárez, P. et al. Fecal ESBL Escherichia coli carriage as a risk factor for bacteremia in patients with hematological malignancies. Supportive care in cancer: official journal of the Multinational Association of Supportive Care in Cancer, 24(1), 253-259. (2016).

22. Uc-Cachón, A. H. et al. High Prevalence of Antimicrobial Resistance Among Gram-Negative Isolated Bacilli in Intensive Care Units at a Tertiary-Care Hospital in Yucatán Mexico. Medicina (Kaunas, Lithuania), 55(9), https://doi.org/10.3390/medicina55090588 (2019).

23. Barrios, H. et al. ESBL-producing Escherichia coli and Klebsiella pneumoniae: The most prevalent clinical isolates obtained between 2005 and 2012 in Mexico. Journal of Global Antimicrobial Resistance, 10, 243-246. (2017).

24. Tamez-Torres, K. M. et al. High prevalence of MDR gram-negative bacteria in feces of healthy blood donors in Mexico. European journal of clinical microbiology \& infectious diseases: official publication of the European Society of Clinical Microbiology, 39(8), 1439-1444. (2020).

25. Merida-Vieyra, J. et al. First Report of Group CTX-M-9 Extended Spectrum Beta-Lactamases in Escherichia coli Isolates from Pediatric Patients in Mexico. PloS one, 11(12), e0168608. https://doi.org/10.1371/journal.pone.0168608 (2016).

26. Abayneh, M., Tesfaw, G., \& Abdissa, A. Isolation of Extended-Spectrum $\beta$-lactamase- (ESBL-) Producing Escherichia coliand Klebsiella pneumoniae from Patients with Community-Onset Urinary Tract Infections in Jimma University Specialized Hospital, Southwest Ethiopia. The Canadian journal of infectious diseases \& medical microbiology = Journal canadien des maladies infectieuses et de la microbiologie medicale, 2018, https://doi.org/10.1155/2018/4846159 (2018). 
27. Hertz, F. B. et al. ESBL-production in Escherichia coli and Klebsiella pneumoniae isolates from Nigeria. Microbiology Open, 8(9), e00816. https://doi.org/10.1002/mbo3.816 (2019).

28. Hassuna, N. A., Khairalla, A. S., Farahat, E. M., Hammad, A. M., \& Abdel-Fattah, M. Molecular characterization of Extended-spectrum $\beta$ lactamase-producing coli recovered from community-acquired urinary tract infections in Upper Egypt. Scientific reports, 10(1), 1-8. (2020).

29. Kawamura, K. et al. ESBL-producing Escherichia coliand Its Rapid Rise among Healthy People. Food safety (Tokyo, Japan), 5(4), 122-150. (2017).

30. Azargun, R. et al. The prevalence of plasmid-mediated quinolone resistance and ESBL-production in Enterobacteriaceaeisolated from urinary tract infections. Infection and drug resistance, 11, 1007-1014. (2018).

31. Saseedharan, S. et al. Epidemiology of diabetic foot infections in a reference tertiary hospital in India. Brazilian journal of microbiology: [publication of the Brazilian Society for Microbiology], 49(2), 401-406. (2018).

32. Bajpai, T., Pandey, M., Varma, M., \& Bhatambare, G. S. Prevalence of TEM, SHV, and CTX-M Beta-Lactamase genes in the urinary isolates of a tertiary care hospital. Avicenna journal of medicine, $7(1), 12-16$. (2017).

33. Møller, T. et al. Treatment with Cefotaxime Affects Expression of Conjugation Associated Proteins and Conjugation Transfer Frequency of an Incl1 Plasmid in Escherichia coli. Frontiers in microbiology, 8, https://doi.org/10.3389/fmicb.2017.02365 (2017).

34. Liu, G., Bogaj, K., Bortolaia, V., Olsen, J. E., \& Thomsen, L. E. Antibiotic-Induced, Increased Conjugative Transfer Is Common to Diverse Naturally Occurring ESBL Plasmids in Escherichia coli. Frontiers in microbiology, 10, https://doi.org/10.3389/fmicb.2019.02119 (2019).

35. Sutherland, C. A., Verastegui, J. E., \& Nicolau, D. P. In vitro potency of amikacin and comparators against coli, K. pneumoniae and P. aeruginosa respiratory and blood isolates. Annals of clinical microbiology and antimicrobials, 15(1), 39. https://doi.org/10.1186/s12941016-0155-z (2016).

36. Teklu, D. S. et al. Extended-spectrum beta-lactamase production and multi-drug resistance among Enterobacteriaceaeisolated in Addis Ababa, Ethiopia. Antimicrobial resistance and infection control, 8, 39. https://doi.org/10.1186/s13756-019-0488-4 (2019).

37. Drieux, L., Brossier, F., Sougakoff, W., \& Jarlier, V. Phenotypic detection of extended-spectrum beta-lactamase production in Enterobacteriaceae: review and bench guide. Clinical microbiology and infection : the official publication of the European Society of Clinical Microbiology and Infectious Diseases, 14 Suppl 1, 90-103 (2008).

38. Dallenne, C., Da Costa, A., Decré, D., Favier, C., \& Arlet, G. Development of a set of multiplex PCR assays for the detection of genes encoding important beta-lactamases in Enterobacteriaceae. The Journal of antimicrobial chemotherapy, 65(3), 490-495. (2010). 